\title{
Verdade em movimento: A Antropologia Recursiva da Divinação Cubana
}

\author{
Ana Caroline Amorim Oliveira \\ Professora da Universidade Federal do Maranhão-UFMA \\ Doutoranda em Antropologia Social da Universidade de São \\ Paulo-USP
}

HOLBRAAD, Martin. Truth in Motion. The Recursive Anthropology of Cuban Divination. Chicago, The University of Chicago Press,2012.

Este livro de Martin Holbraad, antropólogo e pesquisador de religiões afro-cubanas - dedicado a Eduardo Viveiro de Castro e a Javier Alfonso Isasi (interlocutores centrais do autor) - é composto por prefácio, introdução, oito capítulos, conclusão, epílogo e dois apêndices. O problema primordial do livro é (re)pensar a noção de verdade de cunho representacional na Antropologia. Holbraad defende substituir a noção de representação, a que a verdade esta vinculada, pela noção de infinition1, definida como inaugurações inventivas, pois a verdade é um ato de definição que efetivamente transforma o mundo. $\mathrm{O}$ autor justifica a escolha da noção de verdade como objeto de sua análise afirmando que a mesma se refere diretamente a própria natureza do raciocínio antropológico.

Holbraad inicia o primeiro capítulo com uma "longa conversa antropológica sobre o papel e o estatuto da verdade" a partir de uma micro-

\footnotetext{
${ }^{1}$ Holbraad cria essa noção a partir da ideia de invenção de Roy Wagner. (HOLBRAAD,2012:239).
} 
história da disciplina tomando como eixo as preocupações dos antropólogos com a verdade. Após essa digressão da história da Antropologia, Holbraad se centra nos estudos de Roy Wagner, Viveiros de Castro e Marilyn Strathern para pensar sobre a dicotomia antropológica natureza versus cultura. Para Holbraad, Roy Wagner realiza uma radicalização ao tomar o próprio conceito de cultura enquanto alvo de crítica. Holbraad entende que mais do que simplesmente trazer o conteúdo etnográfico para a análise antropológica, o que Wagner esta propondo é uma invenção da análise a partir da alteridade o que envolveria uma semiótica da invenção. Esta implica que tudo(representações e mundo) é significativo. Todavia, Holbraad enxerga uma ausência nesse debate sobre a noção de verdade. Para trazer tal noção para o centro da discussão o autor se utiliza da estratégia recursiva de Strathern, na qual se parte do conteúdo etnográfico para transformar a análise e, então, transformar a própria disciplina. Colocar a questão da verdade no centro da análise recursiva é a tentativa de uma resposta à recusa explícita dada por Viveiros de Castro a tal questão.

No segundo capítulo, Holbraad justifica como objeto de estudo o fenômeno da adivinhação em virtude de estar posto em tal arena etnográfica a noção de verdade. $\mathrm{O}$ autor faz uma crítica a uma perspectiva cética presente nos estudos sobre a adivinhação. O foco do autor não é o debate sobre racionalidade, mas, a cegueira constitutiva em torno da questão da indubitabilidade. Em vez do foco de distinção ser a dúvida, o autor, defende a indubitabilidade da verdade divinatória, pois os oráculos apenas dão respostas verdadeiras. "To doubt oracular truth is to doubt whether it is oracular"2 (HOLBRAAD, 2012: 69). O objeto da descrença não é entorno da verdade da adivinhação, mas sim do caráter divinatório.

$\mathrm{O}$ autor, no terceiro capítulo, apresenta a pesquisa de campo e sua etnografia da adivinhação Ifá. Entretanto, a etnografia é retomada ao longo de toda a obra. A pesquisa de campo em Havana teve como interlocutor principal o babalaô(sacerdote Ifá) Javier Alfonso Isasi. Este é conhecido por sua humildade e prestígio religioso. Ambas as características entrelaçadas com o Ifá. Holbraad identifica a questão da verdade na vida cotidiana dos babalaôs, assim como, uma preocupação difundida com a adivinhação e seu papel na regulação do funcionamento interno da própria religião. Para o babalaô seu comportamento pessoal será guiado pelo oráculo. O que Holbraad denomina como "regulação divinatória da vida Ifá”. Os pronunciamentos oraculares são tanto editais como vereditos: o caminho iniciático apresentado por Orula, orixá dos caminhos, é uma obrigação. Segundo os interlocutores, não são as pessoas que fazem a adivinhação, mas a adivinhação que faz as pessoas. O princípio divinatório, fundamental para a lógica divinatória Ifá, seria a noção de que todas as experiências humanas estão de uma forma ou de outra sob o domínio dos orixás. Para o autor seria uma constituição ontológica mais profunda da verdade divinatória a fusão entre a transparência epistêmica e a autoridade normativa.

No quarto capítulo, Holbraad discute o aparente paradoxo entre transcendência e imanência presente nos estudos sobre religião, em especial, sobre a religiosidade judaico-cristã. $\mathrm{O}$ autor identifica que o uso desses termos nos estudos sobre religiões africanas remete ás preocupações da religião cristã que são diferentes daquela. No entanto, o autor justifica o uso das noções de transcendência e imanência de forma heurística para fornecer o que ele chama de "as coordenadas globais da cosmologia Ifá".

\footnotetext{
2 "Duvidar da verdade oracular é duvidar se é oracular"(tradução livre).
} 
A partir do problema analítico entre transcendência e imanência, o antropólogo faz uma diferenciação entre cosmologia e ontologia no quinto capítulo. Cosmologia remete genericamente a forma como as pessoas imaginam o mundo ao seu redor, o que constitui as relações das pessoas, bem como, as posições das pessoas, e assim por diante. Ontologia se refere, por outro lado, aos princípios básicos que podem ser ditos sobre tais formas de imaginar o mundo, no tocante as abstrações analíticas como semelhança e diferença, continuidade e descontinuidade, singularidade e pluralidade, etc. Em suma, a cosmologia refere-se à descrição etnográfica, e a ontologia, a análise antropológica (HOLBRAAD, 2012: 145). As duas noções estão relacionadas. A cosmologia expressa os princípios ontológicos subjacentes na descrição etnográfica. Ao mesmo tempo, podendo ser distintos já que os princípios ontológicos extrapolam de outros campos etnográficos. Na adivinhação Ifá não existe uma ruptura ontológica, nem uma descontinuidade entre transcendência e imanência. Mas sim, uma continuidade básica entre o além, onde as divindades normalmente habitam, e, o aqui e agora, em que a influência é efetuada durante a cerimônia de adivinhação. Holbraad afirma que um orixá se torna poderoso em virtude de sua capacidade de atravessar a distância de transcendência à imanência e adentrar no mundo cotidiano dos humanos. Dessa forma, o poder divinatório dos babalaôs reside na sua habilidade de evocar tais percursos trazendo Orula para 'falar' durante a adivinhação.

$\mathrm{O}$ autor, no sexto capítulo, propõe uma reversão analítica ao dar ênfase à lógica do movimento das divindades do Ifá forjando a noção de "ontologia móvel" da prática divinatória. Pois, as divindades não percorrem as distâncias ontológicas, pois elas próprias são as distâncias percorridas. A ontologia móvel proposta pelo autor seria pós-relacional, a partir de análise de Morten Pedersen sobre a obra da Strathern, ao alargar o sentido analítico e intensificando as coordenadas conceituais do termo relacional.

No penúltimo capítulo, o antropólogo define o processo de interpretação realizado na adivinhação Ifá. Este é concebido através da interação entre os caminhos do "iré/osobbo"3 e a sequência de perguntas referente a parte interrogatória da cerimonia: os caminhos míticos narrados pelo "oddu" (caminhos de Orula) e a trajetória pessoal do consultor. Essa metamorfose interpretativa dos significados divinatórios não é representacional. A verdade é indubitável e em constante transformação. A verdade divinatória, que emerge do processo de interpretação, gira em torno da metamorfose do conhecimento mítico realizado pelo babalaô fazendo com que os mitos falem com as circunstâncias dos clientes. Dessa forma, a verdade divinatória pode ser conceituada no contexto.

No último capítulo, Holbraad define a análise móvel a partir da premissa de que os significados são um estado de fluxo transformando uns aos outros quando eles se colidem. Mas ao transformar significados os adivinhos acabam por enunciar novas definições e as verdades divinatórias inventam novas definições para coisas novas. A própria ideia de verdade foi redefinida pelo autor diante desse contexto etnográfico ao substituir a noção de representação a que a verdade esta relacionada pela noção de infinition. Definida como inaugurações inventivas, invenções de novos significados. Não sendo predicativos de reivindicação de verdade, pois a verdade é um ato de definição que efetivamente transforma o mundo.

\footnotetext{
${ }^{3}$ Na cerimônia do Ifá o oráculo responde às perguntas do consultante para a identificação do Iré ou Osobbo, em outras palavras, se a situação está ou não favorável para quem está consultando. (HOLBRAAD, 2003 : 52).
} 
Em sua conclusão, o autor sistematiza e define seu método intitulado “ontografia”. A ontografia tem como eixo central a noção de alteridade enquanto diferença ontológica. A importância do método ontográfico se dá em razão de ser uma forma de mapear as premissas ontológicas do discurso nativo.

O livro de Martin Holbraad traz uma proposta intrigante para o pensamento antropológico acerca da noção de verdade: esta enquanto ato de definição que transforma o mundo. $O$ autor tem o intuito de retirar da antropologia, assim como, dos antropólogos, a angústia de ter que falar a verdade. Para, enfim, reconstruirmos nossa capacidade para a verdade não representacional a partir de uma humildade concertada. "It is this humble realization in the face of others' lives-in the face of our ethnography-that precipitates our creativity. Our capacity for truth, then, is a function of this kind of concerted humility 4". (Idem, 2012: 259).

\title{
Bibliografia
}

HOLBRAAD, Martin. Truth in motion. The Recursive Anthropology of Cuban Divination. Chicago, The University of Chicago, 2012.

. Os oráculos de Ifá e a verdade em Havana. Revista

Mana. Rio de Janeiro, Museu Nacional, n.o2, 2003, p.39-77.

\author{
Recebido em 04/09/2016. \\ Aprovado em 25/10/2016.
}

${ }^{4}$ É essa percepção humilde diante da vida dos outros em face da nossa etnografia- que precipita a nossa criatividade. Nossa capacidade para a verdade, então, é uma função desse tipo de humildade concertada (tradução livre). 